\title{
“EN EL FONDO DEL CAÑO HAY UN NEGRITO" DE JOSÉ LUIS GONZÁLEZ: ESTRUCTURA Y DISCURSO NARCISISTAS
}

\author{
POR \\ LUIS FELIPE DÍAZ \\ Universidad de Puerto Rico
}

La aparente simplicidad del sintagma verbal en el título de "En el fondo del caño hay un negrito" nos anticipa la dramática y permanente presencia de la más sorprendente criatura en la inmersa espacialidad. ${ }^{1}$ Se trata de una advertencia titular que deja luego de la rápida y densa lectura del relato el mortificante recuerdo de un ser que en esa profunda lejanía parece esperar el rescate. Aunque después de todo el lector suele mostrarse complacido por el recordatorio de la presencia de ese significante racial en la escatológica profundidad. Así nos lo señala el agrado que regularmente advertimos en los lectores del cuento, quienes suelen expresarse como si se tratara de haber reconocido en el fondo del relato lo más triste y penoso, pero agradable, de su imagen no sólo personal sino colectiva y nacional a la vez. De ahí que el narcisismo tan advertidamente considerado en el cuento se divise no sólo en su proyección temática sino también en el aspecto de la sico-recepción que impone su atractivo formal. ${ }^{2}$ Como es sabido, en la conducta narcisista la imagen reflejada agrada por su peculiar atractivo, al reconocerse en el reflejo mismo

\footnotetext{
${ }^{1}$ Me refiero aquí al verbo "haber" que se asocia con el perpetuo "estar" de la flor de narciso en el agua como señal del estado permanente de un acontecimiento de orden mítico que requiere ser recordado (ritualizado) por medio de la continua narración. Este cuento del escritor dominicano-puertorriqueño José Luis Conzález, surge por primera vez en la revista Asomante 3 (1950). Luego aparece como primer relato de su libro de cuentos $E n$ este lado (México: Los Presentes, 1954). Curioso resulta que en esta versión el niño se llama Macarín. Más adelante el niño también aparece con el nombre de Macarín en la Antología del cuento puertorriqueño Vol. II de Cesáreo Rosa Nieves (San Juan: Editorial Campos, 1959) 415-419. En Cuentos puertorriqueños de hoy de René Marqués (San Juan: Club del Libro, 1959) 83-88, el infante se llama Melodía.

2 Este cuento, como ocurre en las narraciones de gran consciencia de su condición formal, ofrece una proyección en la que se concibe a sí mismo como portador de aquello que se encuentra en su contenido. De ahí que el narcisismo emitido dentro del relato se encuentre en el acto de recepción, de la lectura (en el afuera). Después de todo, el cuento invita al lector a sumergirse en el relato mismo y a inmiscuirse en su condición de lector narcisista.
} 
aquél que se contempla. Este cuento de José Luis González nos ofrece, en tal sentido, consideraciones ampliamente significativas en cuanto al aspecto de la creación literaria misma (lo imaginario y especular del arte) y en lo relacionado al proceso de la recepción espejística del sujeto que, más que contemplar la otredad reflejada, sin percatarse plenamente de ello, se ve y se busca (se crea) a sí mismo. Mayor relevancia adquieren tales implicaciones, sobre todo cuando se advierten aspectos del ser nacional puertorriqueño como sujeto colectivo de gran capacidad creativa, capaz de reconocer mediante ella su identidad cultural misma.

Pero tal resultante en la recepción del relato adviene más bien del quizás imprevisto logro del genio narrativo de José Luis González y del análisis sugerido por el relato mismo, que aqui tratamos de presentar. Por el lado de la consciente emisión del cuento como signo, lo que inicialmente advertimos es el empeño de González en captar la estructura del mito de Narciso en la conciencia nacional puertorriqueña y transmitirlo en su vertiente más poética y literaria. ${ }^{3}$ Por ello que no se trate de una simple transferencia o recreación del arquetipo clásico del narcisismo a la cultura puertorriqueña. Se trata más bien de consideraciones que permiten al cuentista atrapar, a través de la poética que conlleva la intuición artística, la peculiar y esencial estructura, coincidente en este caso con el proceso cultural puertorriqueño en una instancia histórica muy precisa. En ese sentido la narración que aquí nos ofrece José Luis González se nutre de las significaciones del proceso histórico-cultural puertorriqueño de la década del cincuenta. ${ }^{4}$ Conviene por ello considerar además cómo la referencialidad básica que ocupa la problemática en que se sumerge el cuento

3 Aquí establecemos la necesaria relación entre la capacidad creativa (un tipo de textualidad) y la cultura como proceso portador de su propio discurso y como estructura que demanda ciertas producciones textuales. En tal sentido la aparición de este relato no es fortuita sino más bien una necesidad y demanda de la cultura y su historia. Sería esto análogo al individuo en su capacidad onírica considerada como demanda necesaria e inconsciente de lo que le ocurre en la vigilia de la vida real. Así, el discurso literario, al igual que el sueño (discurso onírico), podría considerarse una construcción metonímica de la realidad consciente. Estos aspectos son considerados por Paul Ricoeur en Freud: una interpretación de la cultura (Madrid: Siglo Veintiuno Editores, 1970), y por Hernán Vidal, Sentido y práctica de la crítica literaria socio-histórica: Panfleto para la proposición de una arqueologia acotada (Minneapolis: Ideologies and Literatures, 1984). Tratándose de la consideración del discurso creativo como alegoria de los procesos historico-culturales véase de Fredric Jameson, The Political Unconscious (New York, Cornell University Press, 1981) y The Ideologies of Theory Essays Vols. I y II (Minneapolis: University of Minnesota Press, 1988).

4 Como consecuencia del triunfo del Partido Popular Democrático como grupo de poder hegemónico en la cultura puertorriqueña de las décadas del cuarenta y del cincuenta surge un nuevo proyecto social de urbanizar, modernizar e industrializar el pais, el cual comienza en el área capitalina. Tal proyecto demanda una nueva fuerza de trabajo en la capital, con la resultante de una emigración hacia San Juan tanto de jíbaros blancos del 
es histórica más que de posibles influencias de la mitología clásica o de la adaptación del relato a las teorias freudianas tratantes del mito de Narciso.

Pero, más allá de esta ineludible pertinencia histórica, debemos considerar primeramente tanto el mito como el aspecto sicoanalítico que forman parte de la armazón con que José Luis González construye su relato. Básicamente, para el sicoanálisis contemporáneo (el que parte de Sigmud Freud y continúa con Jaques Lacán), el narcisismo hace referencia a la conducta del sujeto que observa complacientemente su propia imagen expresando así un amor exclusivo por sí mismo. Tal concepción se inspira en una simplificación moderna del mito de Narciso que señala cómo este último al ver la belleza de un joven reflejada en las aguas (la suya propia) se lanza en su búsqueda quedando como señal la flor que lleva por ello el mismo nombre. El mito clásico cuenta por su parte cómo Narciso era hijo de la ninfa Liríope y del dios fluvial Céfiro. ${ }^{6}$ En una ocasión Liríope se presenta ante el adivino Tiresias para conocer el destino de su hijo. Tiresias le responde: "Narciso vivirá hasta la edad madura con tal que nunca se conozca a sí mismo". Otras versiones dan como respuesta del augur: "tu hijo llegará a edad avanzada si no se da cuenta jamás de su belleza". En otras

centro de la isla como de negros costeños en búsqueda de empleos. Surgen, como consecuencia de la confluencia de estos grupos, los arrabales capitalinos y adyacentes en los terrenos más pantanosos y menos solicitados por las clases dominantes. Nuestro cuento cobra sentido ideológico dentro de tal reconocimiento del proceso histórico puertorriqueño de las aludidas décadas. En este trabajo permanecemos, no obstante, dentro de los márgenes fenomenológicos y estructurales del análisis, pero teniendo presente, aunque no se haga mención explícita de ello, una lectura que tiene como base la historia.

- Ha sido la crítica sicoanalítica ya más estructuralista y formalista la que se ha ocupado de la particular concepción del narcisismo que en nuestro trabajo ofrecemos. Véase de Jean Laplance y Jean Bertran Pontalis, Diccionario de psicoantulisis (Editorial labor, S.A., 1974); Georges Bastin, Diccionario de psicologla sexual (Barcelona: Editorial Herder, 1972); James F. Masterson, "Portrait of the Narcissist". The Search for the Real Self (New York: The Free Press, 1988); Igor A. Caruso, Narcisismo y socialización (Madrid: Siglo Veintiuno Editores, 1975); Aiban Hagelin, Narcisismo. Mito y teoria en la obra de Freud (Buenos Aires: Ediciones Kargieman, 1985); La obra más importante en los estudios estructuralistas del sicoanálisis es la de Jacques Lacan, Escritos; especialmente el ensayo "El estadio del espejo como formador de la función del yo tal como se nos revela en la experiencia psicioanalítica" (Madrid: Siglo Veintiuno Editores, 1971). El tema del narcisismo adquiere significativa importancia a partir del texto de Sigmund Freud, Introducción al narcisismo(1914). Exégeta de gran importancia del discurso lacaniano es Anthony Wilden, especialmente con su ensayo "Lacan and the Discourse of the Other", con notas y comentarios, en Speech and Language in Psychoanalysis (Baltimore: The John Hopkins University Press, 1981). También Ellie Ragland-Sullivan en Jacques Lacan and the Philosophy of Psychoanalysis (Chicago: University of Illinois Press, 1987).

' L. Deudi, Prontuario de mitología griega (Barcelona: Ediciones Zeus, 1965); Robert Graves, Los mitos griegos (Buenos Aires: Editorial Losada, 1958); Herbert Marcuse, Eros y civilización (Barcelona: Editorial Seix Barral, 1968). 
versiones se lo ve con la ninfa llamada Eco, quien no podía utilizar su voz sino para repetir lo ajeno. Un día en que Narciso salió a cazar ciervos Eco lo siguió a hurtadillas con el deseo de conversar con él pero incapaz de hablarle primero. Finalmente lo logra y, al hacerle proposiciones amorosas, Narciso la rechaza. Otro enamorado que seguía a Narciso era Amenio quien, al ser rechazado, se mata e implora venganza a los dioses. Es escuchado por Artemisa, diosa de la venganza y la virginidad, quien condena a Narciso a no poder consumar su amor y le hace adorar su reflejo en el agua como castigo. En esa misma versión del mito Eco escucha los lamentos de Narciso, prisionero de su imagen en la fuente, y repite textualmente sus lamentos. Eco se clava una daga en el pecho y su sangre empapa la tierra, de donde nace la blanca flor del narciso con su corolario rojo. Pese a que son varias las versiones del mito de Narciso vemos cómo se destaca, invariablemente, el aspecto de la capacidad de un sujeto en el reconocimiento de su propia imagen y su aceptación o rechazo de la otredad (sugiriéndose que es la mismidad, de ahílo del eco). Tal es la estructura del mito de Narciso que advertimos en "En el fondo del caño hay un negrito".

Para el sicoanálisis contemporáneo, cuando Narciso desprecia el amor de sus seguidores, vive para sí mismo y, sin saberlo, sólo ama su imagen; confunde irónicamente lo mismo con lo otro. ${ }^{7}$ Su actitud erótica se relaciona con el despego de la madre, la búsqueda de su propia identidad (su yo), la diferenciación del ello sicoanalítico, el ingreso a lo imaginario, el sueño y la búsqueda de la muerte, entre otros lugares comunes. Pero quizás sea el aspecto del eros y su contrapartida, la violencia (vinculada al deseo de muerte), ${ }^{8}$ lo que tenga mayor importancia inicial en el narcisimo. Resulta de relevancia también, como se verá hacia finales de nuestro trabajo, que tanto para el mito como para el

\footnotetext{
${ }^{7}$ En el sicoanálisis lacaniano el concepto del otro (l'autre) se relaciona con la construcción imaginaria que crea el infante a partir de su "moi" en el estadio del espejo. De ahí surgirá la manera en que el sujeto se concebirá y se presentará a sí mismo. El Otro ( ${ }^{\alpha} l$ 'Autre") se relaciona desde otra parte con la estructura inconsciente que funciona como significante del otro y como organizadora a través y desde el lenguaje de lo que se prodría concebir como el inconsciente del sujeto. El discurso del inconsciente (formado por el Otro) aparece separado, reprimido, por el sujeto, quien se ha alienado del mismo a través de la relación con su yo ofrecida por su otro imaginario. Se trata de la estructura relacionada y procedente del Orden Simbolico que organiza la "lengua" y el inconsciente de los individuos y la sociedad. Véase Speech and Language in Psychoanalysis de Jacques Lacan Traducción, notas y comentarios de Anthony Wilden (The John Hopkins University Press, 1981).

${ }^{8}$ Eros es el impulso o estructura del deseo que permite a los individuos la construcción de la cultura, pero ese impulso no puede ser llevado a sus extremos ya que tales individuos deben reprimir y sublimar el pleno potencial del principio del placer para ajustarse al principio de la realidad que tiende a exigir una actividad desexualizada. Por ello los impulsos se tornan agresivos y destructivos (Eros versus Tanatos). Véase El yo y el ello y El malestar de la cultura de Sigmund Freud; así como Eros y civilización de Herbert Marcuse.
} 
sicoanálisis, cuando Narciso muere sigue viviendo simbólicamente en la flor que lleva su nombre. Con ello se revela el ritual del necesario sacrificio del yo para su ingreso en lo simbólico y en la inmortalidad que ofrece el arte. En el cuento que aquí nos ocupa, el título mismo queda, al igual que la flor en el mito, como señal y recordatorio de un evento trágico y profundamente poético allí ocurrido, que todos deben recordar y recrear.

Pero, como es de esperarse, José Luis González elabora en esta narración el mito de Narciso de manera muy particular. Ocupando la perspectiva frontal coloca primeramente la situación en que se encuentran los padres del niño y las circunstancias culturales que los rodean, para luego exponer en el trasfondo el drama narcisista del negrito Melodía. En la estructuración superficial de la totalidad del cuento González destaca, además, manteniendo siempre como eje la situación del niño Melodía, otros dos dramas muy singularmente relacionados. Advertimos en el cuento una serie de paradigmas contiguos y sucesivos en función de micro-relatos que nos refieren primeramente al particular drama de los padres del niño, y luego al de la colectividad que contempla desde afuera. La inter-relación de estos micro-relatos nos lleva a entender mejor la situación del negrito.

La primera sección del relato nos proyecta una perspectiva amplia de la miserable situación de los padres, no sin antes, en el párrafoinicial presentarnos ya la acción primordial que le ofrece la dinámica a todo el relato: la contemplación del negrito Melodía de su imagen en el agua. Aprovecha el narrador en lo sucesivo la particular situación de los padres para enlazarla en parte al drama de la colectividad a finales de esa primera sección presentándonos a distancia ese mundo afuerino de "Automóviles, guaguas y camiones". Será a ese espacio afuerino (metonimia de lo capitalino-capitalista) hacia donde se dirigirá el padre en busca del capital para el sustento de su familia, según presenciamos a finales de esa primera sección.

La sección que sigue (la dos) se divide en tres segmentos. En el primero se nos presenta por segunda vez al negrito Melodía en su gesta narcisista. En el segmento siguiente aparece el micro-relato de "Dos mujeres" que presencian con piedad el drama de los negros recién llegados. Más adelante el tercer segmento nos refiere al padre de Melodía ya en su regreso del día de jornada. $Y$, terminando el relato, la tercera sección nos expone brevemente la caída de Melodía en la profundidad de las aguas. Adviértase cómo, en todas las secciones y en sus segmentos, se destaca sucesivamente el sentir de un sujeto (el niño, el padre, la colectividad, las mujeres) que observa una otredad de la cual obtiene una sensación ya sea de amor o de violencia.

Se enlazan en el relato tanto la perspectiva sicológica de los padres y del niño como la sociológica del mundo capitalino de los automóviles, además de la leve proyección del mundo jíbaro representado por las dos mujeres. En el nivel del contenido, de lo que se llama en el análisis estructural la fábula o "historia", el afuera social es visto desde el padre mientras que el adentro familiarindividual es presenciado a distancia por las mujeres. Las relaciones del aspecto 
social, familiar e individual son enmarcadas igualmente, aunque de manera implícita, dentro de una noción cultural del Puerto Rico de la década del '50, según la concibe la ideología del autor. Pero antes de esta vertiente histórica, y ya dentro de la organicidad y autonomía del relato, conviene localizar al narrador y a su autor, quienes observan desde la perspectiva que ofrece la narración o "discurso" el drama de todos los agentes que ocupan su relato. Es en este espacio del punto de vista y la perspectiva donde se nos ofrece lo que podría considerarse el decir oculto del autor y en el que podemos ubicar las significaciones amplias y totalizantes de este cuento de José Luis González. Y, tratándose de estas consideraciones, habría que tener presente más adelante si el cuento se convierte en espacio espejístico (meta-escenario) en el cual el autor se ve a sí mismo en su acto creativo, tal y como le ocurre al lector que se identifica con el narcisismo del niño Melodía.

El cuento comienza ofreciendo una perspectiva familiar, en la que se advierten inicialmente la peculiar relación de los padres de Melodía. Ahŕ el autor destaca una constante en su relato, vinculada al mito de Narciso: el eros como fuerza que define la sicología profunda del individuo. Impone además, y de inmediato, signos de temporalidad y ambientación espacial. Temprano en la mañana el niño Melodía se mira en el fondo del caño, mientras sus padres, quienes acaban de despertar, se disponen a iniciar las faenas de la mañana. La acción clave del primer párrafo (el mirar del niño hacia el agua abajo) resulta en paradigma que obtiene continuidad mediante la noción del despertar de los padres y sobre todo por medio de las peculiares miradas de la mujer al marido. Queda enlazado así el aspecto de la mirada y de lo espejístico al drama de los padres y a la tragedia del niño. Pero en el caso de los padres, contrariamente al agrado que siente el niño al contemplarse en el agua, la mirada conlleva para ellos nociones de desagrado y ruptura.

La mujer despertó sobresaltada, mirando al hombre con ojos de susto. El hombre se rio. Todas las mañanas era igual: la mujer despertaba con aquella cara de susto que a él le provocaba una gracia sin maldad. La primera vez que el le vio aquella cara de susto a la mujer no fue en un despertar, sino la noche en que se acostaron juntos por primera vez.

Se añade a la noción de la mirada y lo especular el aspecto del eros. Ya sabemos, desde el primer párrafo, cómo se trata del narcisismo en el caso del niño, eros que refiere al peculiar atractivo que encuentra el sujeto hacia la imagen que se le enfrenta. (No debemos en realidad simplemente sostener que se trata del atractivo que siente el niño hacia su imagen puesto que desconoce que se trata de su propio reflejo). Y, en contraste con el placer experimentado por el niño al verse, se presenta el malestar que adviene a los padres al encontrarse en sus chocantes miradas. Advertimos en ello la sugerencia del autor de una mirada erótica trunca e insatisfecha que continúa creando un contraste con el plácido encuentro que obtiene el niño de su propia imagen. 
Además del aspecto del reflejo (lo especular) y del eros (dos actividades primigenias, el estímulo visual y el corporal) el sentido del gusto también cobra importancia. Tratándose del niño, se nos dice que "se quedó en silencio en un rincón, chupándose un dedito porque tenía hambre". Tales alusiones al frustrado paladar crearán el enlace que habrá de referirnos a la carestía de alimento que encuentran los padres y el niño esa mañana. Esta insuficiencia (ausencia de placer) del paladar lleva, una vez más, al eros del malestar y a la ruptura, manifiesta en los padres a través de la mirada:

pero se interrumpió cuando vio que la mujer empezaba a poner aquella otra cara, la cara que a él no le hacía gracia que ella sólo ponía cuando él le hacía preguntas como ésa. La primera vez que le vió aquella cara a la mujer fue la noche que regresó a la casa borracho y deseoso de ella y se le fue encima pero la borrachera no le dejó hacer nada. Quizá por eso a él no le gustaba verle aquella cara a la mujer.

Reconocemos así cómo esta ruptura, debida a la ausencia de un eros (ya visual, palatal o sexual), se relaciona de manera más explícita con la violencia que el yo advierte en la otredad que le contempla. (Conviene aquí insistir en que el niño obtiene por su parte satisfacción de la otredad). En este mismo segmento el autor hará extensivo este malestar en el matrimonio al que se desprende del sector social que observa desde el afuera. La lectura nos lleva en esta ocasión a un nuevo paradigma o micro-relato en el que, rebasándose ya el nivel sicológico de lo individual y familiar, se atiende el aspecto sociológico cuando se nos señala cómo al mirar hacia las afueras del hogar (la otredad) ${ }^{9}$ el padre obtiene sorprendentemente un tipo de violencia verbal:

Luego miro hacia arriba, hacia el puente y la carretera. Automóviles, guaguas, y camiones pasaban en un desfile interminable. El hombre sintiendo, viendo cómo desde casi todos los vehículos alguien miraba con extrañeza hacia la casucha enclavada en medio de aquel brazo de mar: el "caño" sobre cuyas márgenes pantanosas había ido creciendo hacía años el arrabal. Ese alguien por lo general empezaba a mirar la casucha cuando el automóvil, la guagua o el camión, llegaba a la mitad del puente, y después seguía mirando, volteando gradualmente la cabeza hasta que el automóvil, o la guagua o el camión, tomaba la curva allá adelante. El hombre sonrio. Y después murmuró: —¡Pendejos!

\footnotetext{
${ }^{9}$ Se trata de una irónica otredad ya que más adelante el padre se entregará inevitablemente a ese mundo afuerino de la violencia y el dinero (espacio del Otro), obteniendo de ello beneficio y placer por medio de la moneda. Así el padre aparece a la larga identificado con la hostilidad del mundo afuerino que lleva a la subrepticia (inconsciente) violencia y ruptura. Tanto la sociedad como el padre se proponen como la estructura inconsciente que el autor (utilizando como mediación el niño) se niega a adoptar. Se trata, como se verá más adelante en el texto, del arte en búsqueda de una espacialidad de orden muy distinto.
} 
Advertimos en este segmento hasta aquí resaltado tres niveles sucesivos donde la figura paterna se encuentra con la mirada violenta de la otredad. En los dos primeros casos se topa con la agresiva mirada de la esposa y en el segundo con la de la sociedad. El padre, sin embargo, y podríamos decir que inadvertidamente, aparece algo unido a ese mundo de la violencia verbal si consideramos que a principios del relato le gritaba al niño: “-iMire ... eche p'adentro! ¡Diantre ‘e muchacho disinquieto!’ Palabras éstas que comienzan a iniciar al niñoen el ingreso del dominio del Nombre-del-padre, del que hablaremos más adelante. Esta violencia verbal y visual del mundo familiar-social que rodea la figura del padre, y que hasta aquí hemos estado señalando, contrasta notablemente con la agradable atmósfera que por otra parte encuentra el niño en su propia e imaginaria espacialidad, tal y como se nos indica en el primer segmento de la sección número 2:

La segunda vez que el negrito Melodía vio al otro negrito en el fondo del caño fue poco después del mediodía, cuando volvió a gatear hasta la puerta y se asomó y miro hacia abajo. Esta vez el negrito en el fondo del caño le regalo una sonrisa a Melodía. Melodía había sonreido primero y tom6 la sonrisa del otro negrito como una respuesta a la suya. Entonces hizo así con la manita, y desde el fondo del caño el otro negrito le hizo así con la manita. Melodía no pudo reprimir la risa, y le parecí́ también que desde allá abajo llegaba el sonido de otra risa. La madre lo llamó entonces porque el segundo guarapillo de hojas de guanábana ya estaba listo.

Adviértase cómo, contrariamente a la situación del padre señalada en la sección anterior, aquí se destaca el principio del placer por medio de la risa espontánea que no se reprime. Mientras en los fragmentos anteriormente discutidos, lo especular, sonoro y palatal era índice del eros de la ruptura y la violencia aquí lo es del deseo de unidad y armonía. De ahí también la constante repetición en esta sección del nombre Melodía, el cual nos refiere al placer de lo sonoro y del arte, como explicaremos adelante. Y tratándose del sonido, ainicios del cuento el intento de contemplación del niño fue interrumpido por la violenta voz del padre, mientras que aquí lo es por el llamado de la madre quien se apresta a proveerle de alimento. Vistos de esa manera, los vínculos de ambos acontecimientos son de claro corte sicoanalítico. Mientras el padre representa los principios del trabajo, la violencia y el rechazo, la madre significa para el niño el placer, la aceptación y el amor. (La madre resulta relacionada así, y de manera muy indirecta, con la placentera imagen que el niño obtiene de sí). Aunque tratándose del caso del padre, muy distante está el niño Melodía de ser objeto del consabido complejo de Edipo ${ }^{10}$ pues, como sabemos, se encuentra en

${ }^{10}$ Con el complejo de Edipo se designa una estructura de la conducta sentimental quelleva al individuo a rivalizar con el progenitor del mismo sexo con miras a obtener un amor exclusivo del sexo opuesto (aunque en el caso de las niñas se habla del complejo de Electra). Se trata de un proceso normal en la evolución de la sicología del niño desde los 4 a los 7 
la etapa pre-verbal. De ahí que el cuentista ubique el niño en la etapa narcisista del surgimiento del yo que corresponde muy bien a ese estadio pre-verbal en que el niño aparece todavía con grandes vínculos a la madre y muy distante de haber asimilado todo el simbolismo que implica el desarrollo del ego y mucho menos de lo edípico y del Nombre-del-Padre. ${ }^{11}$

años de edad. Espećficamente en el caso del niño varón, éste se muestra -pese a su sentimiento agresivo-, gentil hacia el padre (ante la amenaza de ser castrado) para ganar su favor de autoridad que domina la voluntad de la madre. En el caso del desarrollo de la cultura, vista análogamente a la manera en que evoluciona el individuo, el complejo de Edipo se refiere al momento en que se reprime el odio y la violencia hacia la estructura de poder (el padre) y se lo acepta para evitar la violencia y la destrucción. Véase Totem y tabú de Sigmund Freud, el citado libro de Herbert Marcuse. También La violencia y lo sagrado. John Hopkins University Press, 1972, y The Scapegoat (John Hopkins University Press, 1986), ambos textos de Rene Girard.

"Para escapar la poderosa relación imaginaria con la madre, y para permitir que el sujeto se constituya como tal en lo real, es esencial que el niño se una al Nombre-del-Padre (nomdu-père) o la metáfora paterna que está más allá de lo imaginario, en el Orden Simb6lico, según Lacán (obras citadas). Se trata de entrar a la ley del sistema lingǘístico de la sociedad dominante (Orden Simbólico, castración simbólica). Se ingresa también al "significante del Falo" que representa simbolica, y no biológicamente, la separación de la etapa narcisista de la fusión con lo materno. Aceptar el Nombre-del-Padre es aceptar la subordinación a un OrdenSimbolico paterno-social, seria abandonar la relación imaginaria con la madre y el ser objeto de su deseo. El concepto de lo materno es construido durante la etapa pre-espejística y ya propiamente espejística y es parte integrante del yo narcisista; mientras que el padre es internalizado en una etapa posterior (que lleva al complejo de Edipo) como estructura simb6lica que establece los límites y la ley. De aquí que que el padre sea temido y a la vez emulado, es relacionado con la diferencia mientras que la madre se asocia a la mismidad (lo narcisista). En nuestro relato la voz del padre es la que nombra violentamente al negrito imponiéndole ingresar en el Orden Simbólico. Adviértase que mientras el padre llama violentamente al niño (“-iMire ... eche p'adentro! ¡Diantre'e muchacho disinquieto!") la sociedad del trabajo y la moneda igualmente y por su parte reclama con hostilidad a aquél a ingresar en su dominio. El niño, contrariamente a lo que normalmente ocurre en el desarrollo del individuo, segrín el sicoanálisis, indirectamente se niega a ingresar en el ámbito del dominio del lenguaje del padre (que a la larga es el de la sociedad de la moneda) para irse (regresar) en busca de la madre que es el objeto inicial no problemático del deseo. Se trata, como veremos más adelante en nuestro análisis, del autor rechazando por medio del arte el Nombre-del-Padre, el Orden Simbolico y la cultura machista dominante. Se requiere entender cómo por su parte González rechaza en el cuento esta entrada en el Orden Simbólico del plano ideológico del padre, a quien contempla con distanciamiento. El interés de nuestro autor está más bien en su deseo de ingresar en un nuevo espacio imaginario que es el del arte, en el que penetra simbólicamente el negrito. Se trata de la imaginación colectiva que proyecta hacia un futuro rescate del niño. Sobre el aspecto del Nombre-del-Padre y su significado para el análisis de la cultura véase "Lacan and the Discourse of the Other" en Jacques Lacan, Speech and Language in Psychoanalysis ( traduccion notas y comentarios de Anthony Wilden ( Baltimore: The Johns Hopkins University Press, 1981). 
Además de revelarse la dimensión sicológica del niño, también en esta sección número dos se atiende, como señalamos antes, el aspecto de lo sociológico mediante la colectividad que contempla desde afuera el lamentable drama familiar. Luego del breve episodio del niño observándose en las aguas el autor cambia la perspectiva y nos presenta a "Dos mujeres, de las afortunadas que vivian en la tierra firme". Advertimos aquí que si bien es importante en el cuento el aspecto especular del narcisismo y de la apropiación del yo también lo es el de la posesión de la tierra (estableciéndose así asociaciones de ésta con la identidad del yo, la pertenencia a la madre y a la (madre) patria). Ya el título del cuento nos avisa que se trata de la pertenencia y permanencia del símbolo del niño en la espacialidad más escatológica y marginal, espacio del que todos pretenden alejarse. Los padres del niño, quienes viven en el "caño" sobre cuyas márgenes pantanosas había ido creciendo hacía años "el arrabal", y que en este caso representan a los negros, se ven obligados a vivir en esos espacios marginales que los distancian de la seguridad de la tierra firme (es decir, son los más distantes del símbolo de la tierra-madre). Las dos mujeres, por su parte, en representación del jíbaro blanco, observan el drama del destierro y se apiadan desde "la parte máh sequita" de la desgracia de los negros.

En este segmento el cuento continúa dentro de la secuencia de un sujeto que contempla su otredad, esta vez desde el afuera. Pero en este evento las relaciones no son de violencia de clases, o racial, como en el caso de aquéllos que observaban al padre del niño desde los automóviles. Se trata de dos mujeres en representación del símbolo materno, que se apiadan de la llegada y "caída" de los "negroh arrimaoh". Estamos, pues, ante tres grupos muy distintos: los capitalinos del agresivo mundo de guaguas y camiones, quienes miran con desprecio a los del arrabal, los recién llegados jíbaros de "la parte máh sequecita" y los negros del "caño". La tendencia de estos sectores y grupos es la de dirigirse hacia el afuera, espacialidad inconsciente del mundo paterno y del complejo de Edipo, mientras que la del niño -y del cuentista- será la de buscar el adentro, ámbito que se asocia al yo y al narcisismo.

Al ser contrastado con eventos de la sección inicial, este segmento que aquí estamos destacando sugiere cómo las significaciones de violencia emergen al tratarse del ámbito de lo paterno. Ello lleva, por otra parte, a que cobren así relieve privilegiado los aspectos maternales cuando se trata de las dos mujeres y de lo que hemos reconocido como el símbolo de la tierra-madre. Distinguimos de ese modo un espacio desde el cual se expresa la solidaridad, puesto que las mujeres le ofrecen a la madre del niño Melodia las hojas de guanábana que alimentarán a su infante y gratificarán el deseo de su paladar. La alusión a la Virgen a finales del fragmento es el mayor índice de esa privilegiada noción maternal de la piedad que satisface un deseo que más que biológico o social es mítico en cuanto a su reclamo de pertenencia a un orden de mayor significación que el padre y la sociedad.

En el último segmento de esta sección II se alude una vez más al padre del niño ya en su regreso del trabajo. A finales de la primera sección habíamos visto 
cómo el padre del niño se había dirigido hacia ese mundo de la carretera y del ruido de los automóviles. Ahora, en la sección que aquí nos ocupa, sabemos que se trata del mundo de los "muelles", de la mercancía y del trabajo. Se sugiere aquí la partida del padre hacia el mundo del capital para ganar el sustento de su familia, como también su entrega a ese espacio de la otredad afuerina que, según vimos al principio del relato, le tratara con violencia. El padre, en tal sentido, ha tenido que reprimir igualmente su violencia contra ese mundo que denominara de "pendejos" y entregársele, tal y como el hijo, según nos lo revela el discurso sicoanalítico, se entrega al padre, aceptando su ley. Estamos aquí en los ámbitos del complejo de Edipo. ${ }^{12}$ Muy distinta será la situación del negrito Melodía en su entrega al otro del reflejo.

Al regresar, el cansancio en la espalda del padre de Melodía es reconfortado por el sonido de las monedas que palpa con placer en el fondo de su bolsillo:

Al atardecer, el hombre estaba cansado. Le dolía la espalda, pero venía palpando las monedas en el fondo del bolsillo, haciendolas sonar, adivinando con el tacto cual era un vellón, cuál de diez, cuál de peseta.

Habíamos visto antes cómo de la relación matrimonial no se obtenía placer. Éste, sin embargo es obtenido del residuo del mundo del trabajo: las monedas. Y se trata de un residuo que está en "el fondo del bolsillo", sintagma que podría contraponerse con el ya aludido en el título. De aquí quizá la asociación inconsciente que el cuento obliga a establecer entre la pérdida final del niño en el silencio profundo del caño y la ruidosa ganancia monetaria en la superficie. De ahí también la ironía de que, mientras se gana el sustento del niño, éste se pierde en el fondo del caño. A ello se debe que nos haya advertido el narrador que cuando el padre parte hacia el mundo del trabajo "el ruido de los automóviles ahogó el llanto del negrito en la casucha" (subrayado nuestro).

En la sección final (la tres) asistimos al drama de la caída de Melodía al fondo del caño. Se trata de una caída vespertina que connota el ingreso en el inconsciente, en contraste con el matutino (consciente) inicio de la acción en el cuento. El padre, quien diera inicio a la acción que conecta con el mundo afuerino, llega tarde, lo cual se nos presenta como índice del rechazo a lo que él representa. La acción del negrito Melodía al lanzarse al caño puede ser considerada, por su parte, como medida de rechazo a la Otredad representada por el mundo de la violencia del padre. Aunque no se trata de un acto consciente de rechazo propiamente del niño, puesto que éste se encuentra en una etapa preverbal y pre-simbólica que no le lleva todavía a reaccionar ante las acciones del padre. Se podría decir, en ese sentido, que su ingreso en la profundidad del caño se presenta como el destino narrativo que le ha deparado el cuentista como medida de repudio al mundo del complejo de Edipo del padre y de la sociedad

12 Véase nota 9. 
capitalista. ${ }^{13}$ A la larga es el cuentista quien escoge lo escatológico de la profundidad del caño y rechaza el simbolismo (también escatológico) de la moneda de la sociedad capitalista. De ahí que la única alternativa de Melodía (y del autor) sea la búsqueda hacia lo más extremo del interior que compromete con lo más inconsciente y diferente, y con el espacio de la muerte.

Pero hay aquí sin embargo un aspecto de equívoco en el acto de Melodía, pues, por estar en la etapa pre-verbal y pre-simbólica, no posee plena conciencia de su propia imagen. Para Melodía la graciosa imagen reflejada en el agua del caño es la del otro. De ahí que en el plano real el acontecimiento de su carda pueda tener alusiones catastróficas y de pérdida, si no de ruptura total. Pero el interpretarlo así nos limita a un nivel de lectura que no advierte las implicaciones simbólicas del relato. ${ }^{14} \mathrm{El}$ no trascender a tal nivel simbólico implicaría no lograr la lectura narcisista (imaginaria) del cuento que el autor pretende precisamente obtener del lector. Para entrar en tales consideraciones del simbolismo del acto habría que entender el concepto básico del narcisismo que el cuentista parece reconstruir muy bien en su relato, y cómo éste se relaciona con la creación literaria como espacio muy distintivo del arte.

Al hablarse aquí de narcisismo no se hace referencia a una emoción egoísta y negativa (patológica) que enajena de lo externo, de la realidad y con implicaciones de estacamiento o desviación. ${ }^{15}$ Sí, hay en el narcisismo una fijación en lo interno-imaginario que aquí en el cuento tiene sentido, ya que con ello se rechaza la violencia del mundo externo (Orden Simbólico) que domina al

\footnotetext{
${ }^{13} \mathrm{Habrí}$ que preguntarse por qué el niño se sumerge en el fondo del caño. La contestación no está en el niño, puesto que éste no posee racionalidad ni actúa de acuerdo a ella. El deseo del autor lo sumerge en el fondo del caño para adentrarse en el inconsciente y buscar una racionalidad que no se encuentra en el afuera, en el mundo conflictivo del padre y de la sociedad. El niño se va en búsqueda del otro, y el autor se va en la de sí mismo y del arte.

14 Con esta alusión al simbolismo no nos referimos al Orden Simbólico lacaniano antes señalado. Más bien nos referimos a que la lectura no debe ser ejercida a un simple nivel literal sino que se debe alcanzar un segundo orden de significado.

${ }_{15}$ El narcisismo ha sido visto por los seguidores freudianos de la escuela inglesa y americana como un aspecto negativo y enajenante de la conducta humana que aleja del alcance de un yo saludable. En la sicología lacaniana se percibe sin embargo el narcisismo como una consecuencia natural de experimentar la otredad como extensión del yo para así vislumbrar la unidad del ser. En este sentido la concepción narcisista de González, por estar inspirada en la intuición poética y artística, está a tono con Lacán al prescindir del aspecto patologico y enfermizo. No se trata obviamente aquí de una influencia del sicoanalista francés, ya que es poco probable que el escritor puertorriqueño lo conociera a finales de la década del cuarenta o la de principios del cincuenta. El narcismo es una estructura de la conducta humana que puede ser aprehendida de la realidad misma y no necesariamente de la lectura de los textos de Freud o Lacán. Aunque sí es probable que J. L. González estuviese al tanto de las teorías freudianas sobre la sicología humana.
} 
padre. ${ }^{16}$ Mientras los padres se encuentran atrapados en el mundo de la alteridad, el niño, como se entiende en el sicoanálisis, busca inconscientemente el encuentro y la identidad con una imagen alterna que viene a coincidir con su propio yo. Los padres, por su parte, se buscan en la otredad y en la imagen alterna (el hombre busca la mujer) sin encontrarse (más bien se extrañan y se distancian). El niño, entendiendo que sus acciones representan más bien la visión del autor, al retrotraerse y verse armoniosamente en la otredad de su imagen se lanza inconscientemente a la búsqueda de su mismidad, quizás para nocaer en la contradicción y enajenación de sus padres y para no comprometerse con el mundo capitalista del afuera. La verdad para el infante, contrariamente a lo que creen los padres, parece no estar afuera sino adentro. Y como ya hemos señalado en nuestro análisis, ese mundo de la otredad del afuera se encuentra controlado por la ruptura y la violencia, sacudido por la lucha racial y de clases sociales, y carece de una erótica armoniosa que ponga al individuo en contacto consigo mismo y con la otredad. El inconsciente rechazo del niño a ese mundo adquiere entonces sentido y es señal de la conciencia del autor.

Para el discurso ya propiamente sicoanalítico, en el estadio narcisista todo infante ha de pasar por la etapa (pre)espejística en la que solamente es capaz de explorar desarticuladamente lo externo con la mirada, el oído y el gusto y con muy poca, si no ninguna, capacidad conceptual. ${ }^{17}$ Aqui el niño se encuentra en

\footnotetext{
${ }^{16}$ El Orden Simb6lico se relaciona con los códigos organizadores de la estructura profunda (inconsciente) de los sistemas sociales y culturales. El lenguaje pertenece a este orden. Es a través del lenguaje que el sujeto puede representar deseos y sentimientos y es dentro y mediante él que es representado y constituido. Lóvi-Strauss sugiere que las leyes sociales que regulan los lazos matrimoniales son estructuradas de manera similar al lenguaje. El sujeto a ser ya tiene un lugar en el lenguaje, es situado en una red de símbolos inconscientes que organizan y estructuran su ser. No obstante el Orden Simbólico no se encuentra necesariamente en el afuera. Se trata de una construcción mental que el individuo obtiene desde lo real. En nuestro relato, el padre del niño tiene que aceptar el Orden Simbolico de la sociedad capitalista-capitalina puesto que ya ha internalizado dentro de una concatenación la noción de un Poder que es el Nombre-del-Padre, lo cual le predispone con aquel orden.

${ }_{17}$ Con la etapa espejística Lacán se refiere al evento ocurrido entre los seis y dieciocho meses en que el infante comienza a reconocer su imagen en el espejo; lo cual equivale a decir, etapa en la que comienza a desarrollar su ego y a diferenciar su yo del no-yo. Tal evento se refiere al drama del niño que se reconoce en el espejo y se fascina con su imagen. En esta etapa el infante comienza a tener contacto con su corporeidad (que asocia con la de la madre) para tomarla como objeto de su deseo. Para el 1934 Lacán ingresó a la Société Psychanalytique de Paris y en el año 1936 presento su trabajo sobre la etapa del espejo al Congreso Internacional de Psicoanálisis en Mareibad. El contenido de su pensamiento sobre la etapa del espejo se presentó en la Encyclopédie Française de 1938. En sus Escritos (1966) aparece una versión revisada presentada en el Congreso Internacional de Psicoanálisis de Zurich (1949).
} 
lo que se concibe como el Orden Imaginario ${ }^{18}$ que se relaciona con el campo de la fantasía y las imágenes, y donde comienza a desear la presencia de la madre quien se va ausentando mientras el infante se haido independizando y cobrando conciencia del yo y del no-yo. El arquetipo de esta etapa pre-verbal es la del niño frente al espejo fascinado con su propia imagen. De ahí que el Orden Imaginario se relacione con las estructuras pre-verbales y el apego al seno de la madre. EI niño "descubre" (más bien intuye) su cuerpo en esta etapa como espacialidad de la felicidad materna (mismidad), distinta al cuerpo de la otredad (el padre, y la espacialidad del afuera). No logra, sin embargo, distinguir su separación real de la madre ni que ella es parte de ese afuera, del padre y la sociedad. Es por eso que a la larga, y ya tratándose del negrito Melodía, el único espacio que puede asegurar la unidad, la permanencia y la armonía es el de la muerte. Y ésta entendida por el lector como drama (trágico) que habrá de quedar codificado para la literatura y la memoria.

En los inicios de la etapa que lleva al Orden Imaginario, el infante carece de coordinación física durante los primeros seis meses, pese a sus desarrolladas capacidades visuales. Esta experiencia pre-espejística es localizada por el sicoanálisis como fuente de la común fantasía o sueño (lo imaginario) del cuerpo fragmentado que se obtiene mediante el reconocimiento de la madre y de sus actividades con el infante (abrazos, besos, manutención). Una búsqueda de la totalidad sigue en la etapa ya propiamente espejística subsiguiente (de seis a dieciocho meses), la cual establece el deseo por la unidad, que se encuentra en la imagen (Gestalt) en la que mentalmente el niño ha aprendido a proyectar su yo a partir de su noción de unidad con la madre. Se trata del primer acto coherentemente simbólico (en el sentido de separar la imagen de lo real) del niño. Es en esta instancia donde se encuentra, desde el punto de vista sicológico, el niño de "En el fondo del caño ...".

En realidad, desde ese punto de vista, todo individuo ha de pasar en su desarrollo normal por la etapa espejística que crea la noción básica de su yo y de la otredad a partir de la relación con lo materno. Luego de esta etapa narcisista inicial todo infante debe comenzar a conceptualizar y simbolizar a partir de su ego ya formado y diferenciado del no-Yo. De ahí que los impulsos primarios de ese yo y sus deseos de permanencia con la madre tengan que

${ }^{18}$ El sicoanálisis lacaniano nos habla de los ordenes Imaginario, Simbolico y Real. El Orden Imaginario trata del campo de las fantasias y las imágenes. Se inicia en la etapa del espejo y se extiende hacia la adultez. El Orden Simbólico se refiere a la esfera de los sistemas simbolicos incluyendo los culturales. El lenguaje pertenece a este orden y es éste el que construye las significaciones que gobiernan al individuo. El Orden Real trata del dominio fuera de la conciencia del sujeto y fuera del Orden Imaginario (tal y como la concibe el sujeto pensante mismo): Jacques Lacán "Discurso de Roma" (1953); Anthony Wilden. The Language of the Self (JohnHopkins University Press, 1968); y EllieRaglandSullivan, Jacques Lacan and the Philosophy of Psychoanalysis (University of Ilinois Press, 1987). 
posteriormente ser postergados a la Ley del padre para ingresar en lo que se entiende como el complejo de Edipo. En el relato, José Luis González, movido más por la inspiración poética que por demandas de lo verosímil-real, propone la necesidad de permanecer en la etapa narcisista como medida de protección de la alienciación que representa el ingreso en el Orden Simbólico de la sociedad y la historia dominada por el racismo y el clasismo. González coloca al niño en la transición del infante que acaba de cobrar toda su constitución narcisista (reconocimiento del yo) que lo llevará a diferenciarse del afuera y del mundo. $Y$ tal diferenciación la logra ya que ese mundo se encuentra abordado por la violencia y la agresividad que le impondría un inconsciente deseo de hostilidad hacia la madre (el ya adoptado por el padre) y la aceptación marginada y sumisa del arrabal.

Pero lo que conviene entender inicialmente es la etapa pre-verbal y preespejística en que Melodía se encuentra. Desde ella se apresta a separarse de la madre y a cobrar conciencia básica (verse en el espejo) de la independencia de su yo, como propiamente pasa a finales del relato. Para el sicoanálisis esto en realidadocurre en todo infante que debe abandonar ilusoria eimaginariamente su dependencia de la madre para darle unidad a su ser, a su otro yo. Antes de ingresar en el Complejo de Edipo o en el Orden Simbólico del Nombre-del-Padre (etapa ya de represión y socialización) debe cobrar conciencia de su yo para a partir de ahí desarrollar su personalidad. Los padres del negrito Melodía obviamente, aunque tal consideración esté fuera de lo relatado por J. L. González, ya han pasado por la etapa espejística y han alcanzado la etapa simbólica del Nombre-del-Padre y por lo tanto la pertenencia al Orden Simbólico. El ingreso a esa nueva etapa los ha llevado a perder su identidad imaginaria, con la resultante de haber obtenido del ingreso en ella una otredad que sólo puede ofrecerles un eros trunco e insatisfecho que les lleva a un subrepticio e inconsciente deseo de violencia. Por dicho proceso habrá de pasar todo infante excepto Melodía, quien con su caída lo interrumpe. De ahí que el descenso del niño y su permanencia en el fondo del caño represente, además del rechazo al mundo violento y alienado del padre, el deseo de pertenencia a un espacio de origen, anterior a toda entrega a la Ley tanto paterna como social. Se trata de un deseo de regresar al eros original de la madre (tierra), que por su condición racial ahora parece haberse también perdido, quedando solamente lo más subordinado y marginal (el caño), espacio del que irónicamente se nutrirá triunfalmente la ideología del artista. Así la movilidad del niño queda asociada con la labor del artista, la cual le reclama en este tipo de sociedad el refugiarse en un espacio imaginario que le permita distanciarse y superar el mundo de la violencia y de las imposiciones de la ideología monetaria del Orden Simbólico dominado por la sociedad capitalina.

Tomado así en consideración el acto de Melodía se nos revela como el deseo del autor de ingresar al espacio originario de la imagen y de encontrar el espacio que define la escritura. Es a partir de ahí desde donde el autor divisa y concibe la otredad de la sociedad y la historia, aquella que inadvertidamente se ha 
entregado, como el padre de Melodía, al placer y al eros del capital. El Orden Simbólico que domina a los individuos y la historia es visto en el relato de ese modo desde la etapa imaginaria en que se ubica la conciencia del artista. Se trata de un Orden Imaginario que se identifica con y se ubica en la espacialidad marginal y escatológica del caño y el arrabal, espacio creado y a la vez rechazado por las contradicciones de esa sociedad del Orden Simbólico. De esa zona marginal todos, menos el negrito Melodía (trasunto del autor), pretenden separarse. Así, para el autor y su personaje, la zona del caño es asociada con el arquetipo del agua y la madre (espacio de encuentro del reflejo y del verdadero eros).

Cabe entender así cómo esa sociedad afuerina, espacio del capitalismo, se convierte en el centro de la oficialidad y del trabajo a donde todos deben ingresar (es el Poder). Tal sociedad, al apoderarse del Orden Simbólico y organizarlo, les impone a los individuos la perspectiva de ver despectiva y violentamente lo que concibe como la marginalidad y el afuera (el arrabal, la pobreza, los negros; en un nivel más profundo, la mujer y la madre). Se trata de un poder clasista y racista absorbente que proyecta y propone la violenta otredad y la diferencia hacia un espacio (el arrabal) que él mismo ha creado y que surge de sus propias contradicciones.

El cuentista por su parte no ha presentado su relato desde esa perspectiva del poder oficial (espacio del padre). La perspectiva de su saber, ética y eros se ubican más bien en la espacialidad marginal del oprimido. Desde la aceptación de las zonas del caño y la negritud, González nos presenta las afueras del mundo capitalista como otredad carente de verdadero eros familiar. El acto de Melodía nos resulta en tal sentido una vez más un proceso superado en el que el individuo cobra conciencia de su propio ser, se niega a entregarse a las zonas del placer fundamentado en el capital (las monedas en el fondo del bolsillo), para ingresar en el espacio de la memoria y de la imaginación, es decir, en el espacio del arte. Mediante tal proceder narrativo el artista alcanza una estética y eticidad de orden muy diferente al impuesto desde afuera por la historia de las clases dominantes, y en la que se mantiene la identidad poética del niño(el sentimiento de lo nacional) en suspenso y en espera del rescate.

Interpretado de ese modo reconocemos cómo José L. González nos lleva en su relato a la creación de un nuevo sujeto infantil, diferenciado de la figura del padre y más a tono con la necesaria liberación del eros del arte (Narciso). El padre ha sido devorado por el poder oficial, y desde dentro de ese poder no ha logrado superar el complejo de Edipo. La figura paterna es así proyección de los individuos que en esa sociedad se encuentran alienados de su verdadero ser o subjetividad, de su propia imagen y de su cuerpo. Lo que se revela en la mirada de ese ser alienado es la imagen de la otredad cargada de violencia pues ha perdido el ideal narcisista de su yo y de su mismidad como mediación necesaria para el control de sí mismo, de su propia corporeidad y conciencia y para superar la sociedad del capital que invita a la alienación. El arte, en ese sentido, en su constitución de signo que posee conciencia de sí mismo como imagen, se propone 
como espacio idóneo para refugiarse (tal vez combatir) el discurso dominante (el Nombre-del-Padre) de la cultura alienada. Por ello que el arte se conciba como práctica narcisista que libera al individuo de la alienación social, dotándole de un eros que se basta a sí mismo y colocándole en un Orden Simbólico de privilegio, muy distinto al del padre y la sociedad. 
